\title{
Tracing Contradictions of Neoliberal Governmentality in Tijuana's Sex Industry
}

\author{
By Susanne Hofmann (State University of Campinas/ UNICAMP)
}

\begin{abstract}
My main concern in this article is to illustrate contradictions that neoliberal governmentality produces in the context of sex work in Tijuana. Neoliberal governmentality is a practice of ruling people that interweaves aspirations of individuals with the demands of the market. By theorising governmentality in the context of sex work in Tijuana, it is my intention to move beyond the limited discussion of voluntary versus forced prostitution, in order to stress that sex work has become entangled in ambiguous and simultaneous processes: on the one hand, it can generate personal empowerment and agency, and on the other hand, it demands the individual's subjection to a neoliberal market regime. The article will explain the liberties allowed by Tijuana's sex industry, and elucidate why sex workers prefer managerial sex-work arrangements to personalistic ways of selling sex based on pimps as intermediaries. Despite challenges of selling sex, the income generated from sex work at the US-Mexico border allows many women to create new lifestyles. Sex work is used as a strategic means to realise a project of self-actualisation, which is linked to the desire for economic well-being and upward social mobility. Drawing attention to the complicated entanglements of personal strategies and aspirations of sex workers in this particular locale with neoliberal governmentality, the article demonstrates that sex work can simultaneously be a site of oppression and exploitation, and a stepping-stone to personal advancement.
\end{abstract}




\section{Introduction}

My main concern in this article is to illustrate contradictions that neoliberal governmentality produces in the context of sex work in Tijuana. Neoliberal governmentality is the practice of ruling people that interweaves aspirations of individuals with market demands. ${ }^{1}$ Foucault (1982) describes how, with the emergence of liberalism, governments' demands on the individual behaviour of their citizens to prudent self-conduct were converted to accommodate an economic project. Liberal techniques of governance began to focus on the generation of a population of subjects that were bound to economic paradigms in their thought and behaviour. A crucial component of neoliberal governmentality is its use of the capacities of free subjects to achieve its purposes and goals (Lorey 2006). Freedoms - the freedoms of the market are integral to neoliberal governmentality, which operates on interests, desires, and aspirations, rather than through rights and obligations (Read 2009; Dean 2010). Subjects are not subjugated simply by means of obedience but have become governable in their personal desires.

The current neoliberal governmentality is concerned with the shaping of human conduct towards economic productivity. Neoliberal governmentality is a governmental technology that aims to produce subjects as individuals and as autonomous agents of their lives who adopt a prudent and calculative attitude towards risk, taking sole responsibility for their actions (Inda 2006). Individuals' lives and work projects are to become personal projects of self-making (Rose 1999; Salecl 2004; Lemke 2008), which are to be entrepreneurial (Bröckling 2005) and geared towards productivity in correspondence with current market demands, as well as towards efficiency.

This article shows how the aspirations of female sex workers in Tijuana have become intertwined with the neoliberal appeal to consumption-centred self-creation. I will

\footnotetext{
1 'Neoliberal governmentality' is a mode of rule, or a governmental technology, that operates through self-enhancement techniques. It differs from disciplining modes of governance that draw on physical repression or containment.
} 
delineate how Tijuana's sex industry currently allows a significant degree of selfdetermination in sex work and control over activities performed, thus also allowing some women to achieve their personal projects of self-realisation and upward social mobility. At the same time, women are not given the chance to influence or transform the foundational set-up of the industry to their own benefit, nor have they been able to gain recognition as speaking subjects with political representation or transformative powers.

The fieldwork for this study was carried out in two periods totalling ten months between 2006 and 2008. The basis of this article is a set of twenty-five recorded, semistructured interviews that I conducted at the Department of Health Control (Departamento de Control Sanitario, DHC), which operates a medical centre for sex workers inside the Zona Norte, Tijuana's red light district. This article focuses on sex workers who are legally registered with the DHC, and hence possess an up-to-date 'health card' (tarjeta sanitaria) or work permit, which is issued by the DHC. There are significant numbers of sex workers in Tijuana working without the 'health card,' whom I was able to access through collaboration with a local NGO that carries out health research relevant to sex work. ${ }^{2}$ In addition to those institutional settings, I was able to visit a range of sex establishments during my fieldwork for the purpose of ethnographic observation. No formal interviews were, however, conducted in those venues. Some encounters with sex workers were mediated through a local NGO that works with exsex workers. Those conversations were later reconstructed from memory. All sex workers I talked to worked without pimps according to their own statements (even though some had done so in the past). In Tijuana's red light district, independent sex workers work alongside women selling sex through intermediaries.

\footnotetext{
${ }^{2}$ I have addressed some aspects of the work situation of non-registered sex workers in another article (Hofmann 2010).
} 


\section{Discourses of Individuality, Choice, and Modernisation in Tijuana's} Sex Industry

Tijuana's sex industry experienced a process of modernisation and an image clean-up in the early 1990s. Pressured by the government's plans to regenerate the city centre and relocate the red light district into a secluded suburban area, sex business managers and owners united in expressing their opposition to those plans, and instead offered to invest heavily in their establishments and the surrounding infrastructure, such as streets, pavements, and illumination (Cornejo 2002). The venues were subsequently refurbished and redecorated. The outcome was a clean, embellished, and illuminated red light district that was able to transmit notions of transparency, modernity, and safety to the US clientele. The dark alleys and dirt roads disappeared, and the red light district could now be presented as trustworthy to the foreign visitor, promising $\operatorname{him}^{3}$ a safe leisure experience.

The state of Baja California has one of Mexico's oldest systems of sex-work regulation. A registry of sex workers has been maintained since the 1980s, when the health clinic in the red light district opened. US health officials and policy makers feared that the sex trade in the border city of Tijuana could contribute to an uncontrollable dissemination of sexually transmitted diseases (STDs) north of the border, and they put pressure on Mexican health institutions along the border to become active in HIV research and prevention. In 2005, sex work regulation in Tijuana was overhauled, making STD testing compulsory for sex workers (McKinley 2005). Namely, with sex work being legal in the Mexican state of Baja California, city authorities hoped that compulsory health testing for sex workers would ensure STD prevention on both sides of the border.

\footnotetext{
${ }^{3} \mathrm{I}$ am using the male personal pronoun here, since in contemporary Tijuana men represent the sex industry's main clientele, purchasing sexual services from female, as well as transgender sex workers (see Castillo 2002).
} 
In the context of health concerns with regards to the border crossing of STDs, the behaviour and attitudes of sex workers became the focus of governance. Binational health teams started educating sex workers in safer sex, sexual health, and the prevention of HIV and other STDs. Sexual health trainers used motivational interviewing techniques and skill-building exercises with sex workers, and gave sexualhealth briefings and counselling sessions (Patterson et al. 2005). Medical sociologist Regina Brunnett (2009) contends that health discourses are not exempt from neoliberal socio-economic transformations. Namely, she argues that individual and collective health have increasingly become discursively constructed as an 'economic object' requiring 'calculated investments' and measurement in accordance with 'economic efficiency criteria' (Brunnett 2009: 15).

Through specialised sexual health education, sex workers became exposed to the technologies of the self that are characteristic of neoliberal governmentality. Lemke (2008: 55) denotes that neoliberal governmentality is a practice that promotes a rationality that is both 'rational-calculating and responsible-ethical.' In neoliberal health discourses, this rationality is applied to bodies in the form of practices of selfcare, aiming at the maintenance and/or increase of the productivity of those bodies in the service of the capitalist market's demands. The body is one of the most significant resources determining an individual's performance in the market; it therefore must be subject to practices of self-inspection, self-monitoring, and self-care in order to secure economic productivity. Specialist health training, informed by neoliberal health discourses, has steered sex workers to become self-regulating individuals who are responsible for their own healthcare, thus purchasing services and medications marketed at them.

When conducting fieldwork in Tijuana's red light district, I was struck by the neoliberal discourses justifying the passing on of responsibilities and risks to workers in the industry that circulated in the sex industry. Women work as self-employed workers in adult establishments, many of which provide separate hotels belonging to the same owner-group. While clients are picked up in nightclubs, sexual services 
beyond lap dances and strip shows take place in the hotels. I was told by many women that they appreciated the way Tijuana's sex industry was run. Most women found that the clubs where they picked up clients were good working environments: venues were clean and safe, and their bosses and work colleagues treated them in a respectful and friendly manner. In an interview, Paula, ${ }^{4}$ who was in charge of introducing and training newly-arrived women in Club Angel, said:

The word [about Club Angel] spread. Women travel back and forth and say if you go to Tijuana, go to this place because there it is safe, there are no problems, they will look after you. It is clean. And the work schedules are flexible, we work eight hours, and if you don't feel well and ask for permission, they let you go. The week consists of five working days, but if you don't manage to do them all, they won't force you. (Paula, 20, from Monterrey)

To newcomers, Paula communicates the business' values of friendliness and respect, emphasising that the owners search for women who share these values. The 'friendly and respectful' women who are selected, she goes on to explain, will be given priority and treated well, because 'the idea is, if the women are content, they will stay and we will have customers.' Thus, according to Paula's narrative, the well-being of women has become part of the establishment's business strategy. Nikolas Rose (1999: 62) has analysed styles of management that take the workers' subjective experience into account. Human-resources managers realised that workers' attitudes towards their work and the company have a significant impact on productivity and efficiency, and hence they began to integrate workers' subjectivity into their managerial strategies. Workers' contentment at work, their feelings of control over their work, and their sense of cohesion within their teams became a focus of managerial concern. On the one hand, this social technique of management constitutes a democratisation or humanisation of

\footnotetext{
${ }^{4}$ Both personal names and the names of sex establishments have been changed in order to guarantee the anonymity of research participants.
} 
work. On the other hand, as Rose makes us aware, it simultaneously attempts to align the wishes, needs, and aspirations of each individual worker with the objectives of the enterprise.

In Paula's view, the women's agency to choose between different clubs and different contracts within the red light district had a noticeable effect on the way they are treated there. Many of the sex workers I talked to confirmed that they were indeed treated in an appreciative and accommodating manner by the third parties of the Zona Norte. As sex worker Tamara pointed out:

Where I work, women are well respected. There is chit-chat, scandalmongering, gossiping, and blather, but it is all good-humoured and there are no sexual undercurrents or anything like that. The relations between girls, waiters, and managers, and the other employees there are very good and with a lot of respect. [...] I am never forced to go with any client. If one behaves badly, I talk to the security and they kick him out. (Tamara, age unknown, from Tapachula)

Respect from owners, managers, and staff was of primary importance to all sex workers I talked to. Adaptability of sex work to individual time management, safety in terms of protection from violent abuse, as well as ensuring reproductive health, and the prospects for self-determination in sex work made Tijuana's sex industry attractive to many women. Women are given a series of options to choose from with regard to their personal work schedules. Sex work in Tijuana is promoted by business owners as a type of work that responds to women's individual needs and aspirations. Amaya recounted from her experience of working in a sex club:

You make the rules about what you are going to do here. If you like to dance or fichar [hostess], go upstairs [sell sex], you can do what you like. It is your decision. (Amaya, age unknown, from Puebla) 
The idea of being in charge of one's own 'business' appeals to women, as Paula put it: 'I am well here, because I can work here and do my own thing.' In Tijuana's sex industry, women are encouraged to become entrepreneurs who set the goals they want to achieve and who manage sex work according to their individual terms and conditions. All the modalities of sex work in the red light district are framed in the terms of individualism and individual agency. Within a range of services, women choose the ones they offer. Amongst different work rotas, they choose the one they prefer. Women choose the clients they want to go with. Tijuana's sex industry offers a range of possibilities to women who are 'free' to select according to their own preferences, thereby communicating values such as the autonomy of individuals and their rationality. Choice is expressed as the exercise of the individual's autonomous will.

Staff trainers like Paula communicate these values of personal choice and individuality to the newly arrived. In conversation with me, Paula stressed the individuality of the experience of sex work, which cannot be compared or generalised. She made statements such as, 'We are all different from each other,' 'One will always do what one wants,' 'Everyone lives how she likes,' 'Everyone has a different perspective,' and 'We are all quite different.' However, in the course of making individual choices in sex work, sex workers are also considered to be individually responsible for their own experience in the industry. A professional sex worker is expected to be positive and transmit good vibes to customers at all times. If she is not in the mood for sex work, it is up to her to either control her mood or withdraw from work. It is suggested to her that not feeling well is her own fault. Women who experience conflicts with clients are seen as having difficult personalities.

Women also have full liability for running and maintaining their individual enterprise, and must thus manage all work-related risks themselves. They are responsible for validating their health cards and carrying out the obligatory health checks. They must pay for all the staff members' wages (in the form of tips), otherwise they risk being sacked. Furthermore, they must fulfil the contract they have arranged with the client 
and deal with arising problems. There is no organised protection that women can rely on in the case of a disagreement regarding the sexual contract between sex worker and client; instead, they must solve the situation themselves. Security inside the hotels where the sexual transaction takes place is individualised instead of being ensured by the owners of those premises. Sex workers have to make their own arrangements for possible emergencies that could occur inside the hotels, and many of them pointed out that receiving support or protection from anyone inside the red light district would only work on the basis of a financial exchange. Hence, if a woman wants a hotel staff member to react to her screaming and support her in the case of an emergency, she must leave a tip every time she works there to ensure that this security backup will work when needed. If women get into trouble while working inside the hotel rooms, it is considered to be entirely their own business.

Tijuana's sex industry has invested in an image that communicates cleanliness, modernity, transparency, security, and control. Attempting to counteract the negative image of their establishments as sleazy and dark, poorly policed and dangerous, managers of upscale venues have installed cameras in hotel reception areas and corridors, conveying the idea of security, transparency, and control to both women and customers. Along with these efforts to transmit transparency, modernity, and safety to the US clientele, sex work was introduced to women as a kind of work that could be practised in a way that was safe. Who or what do these cameras actually protect? The obvious objective seems to be that disruptive or rampaging clients can be detected and kicked out. Most conflicts, however, arise within hotel rooms, where no cameras are installed for privacy reasons. In terms of personal security during sexual transactions, it is important for women that they can exit the rooms at any time without depending on clients or hotel staff to open the doors. Women preferred hotels with doors that cannot be locked and thus could be opened from both sides in the case of emergency. ${ }^{5}$ The installation of cameras in foyers and corridors is not an effective means of guaranteeing

\footnotetext{
${ }^{5}$ Women disliked hotels that hand out keys to clients when registering, since they can lock them from the inside. In some establishments, only the manager possessed a second set of keys to open those doors in case of emergency.
} 
women's security. Appropriate room-door design is far more significant from the women's perspective. Thus, the cameras merely have a psychological effect and function in terms of making employees and clients feel secure, safe, and protected, while glossing over the fact that security, safety, and protection are in fact considered everyone's own (private) business.

Tijuana's sex industry allows women to avoid sex work arrangements based on personal relationships; sex workers are not subject to what O'Connell Davidson (1998: 17) calls the 'personalistic power' of a third party (emphasis in original). While sex workers in Tijuana's red light district do not need pimps as intermediaries between themselves and clients, they are still exposed to domination by managers in the workplace. While in personalistic sex work arrangements the modalities of sex work are enforced by individuals controlling a small number of women, Tijuana's sex industry is directed by managers who determine a menu of modi operandi and protocols for a multitude of workers operating around the clock. Most women I talked to preferred managerial sex work arrangements to personalistic ones and considered their self-entrepreneurship progressive in comparison to women who sold sex with the mediation of a pimp. They valued the choice, flexibility, and self-determination that sex work in Tijuana allowed them. However, the managers' objective (i.e. the absorption of the surplus value generated by sex workers) remains unchallenged in managerial sex work arrangements and the modalities of those work arrangements and contracts are still largely outside of women's determination.

\section{Self-Determination in Tijuana's Sex Industry}

Tijuana's sex industry was considered an advantageous sex work location by a majority of the women I talked to and who had work experience in other Mexican cities. Apart from significantly higher earnings at the border, the advantage was very much linked to the way in which commercial sex is organised in Tijuana. One aspect that women 
found indispensable was self-determination regarding one's work schedule, money handling, and personal work organisation.

One characteristic of Tijuana's red light district is that rather than in brothels, most women work self-employed in clubs, bars, or cantinas where they pick up clients whom they take out to hotels for sexual transactions. Leticia, who has sold sex in Mexico City as well as in Tijuana, referred to slavery when talking about brothels (casas de citas) she worked for in central Mexico:

\begin{abstract}
A brothel is very different from a bar. In a bar I get by alone, I don't have to give money to anyone. It is my money. In a brothel, half the money is for the house and the other half is for me. This is slavery. It is also slavery because the work is very hard. Here it is alright. The owners and bouncers might appear to be slave drivers when they say 'you can't go home yet,' or 'you have to work here in Club Angel,' but this is minimal because the rest is our work and our money. (Leticia, 38, from Mexico City)
\end{abstract}

In this extract, Leticia touches on issues of control and self-determination in sex work. Being paid directly by a client and being able to handle money herself rather than through a third person is absolutely crucial for Leticia, as for the majority of sex workers. The bars and clubs in Tijuana's red light district are run differently from brothels. ${ }^{6}$ Sex establishments charge workers 25 percent of each table dance, and often there is also a set number of fichas (drink coupons) that women have to acquire throughout a work shift. Each ficha is worth between US\$3 and US\$4.50 (depending on the establishment), which must be paid by sex workers, if insufficient clients are

\footnotetext{
${ }^{6}$ This does not mean that brothels do not exist at all in Tijuana. There might be hidden brothels in other areas of the city, which I did not have any access to. Also, some of the gentlemen's clubs might be run in similar ways to brothels, but I did not have any major insight into one of those venues during my fieldwork.
} 
available. ${ }^{7}$ However, women have sole command over the money they charge their clients for the sexual services they provide.

What the women disliked about brothels is the fact that prices are negotiated between the client and a third party, which could be the brothel owner or a madam. It is the third party who charges the client and returns to sex workers only a determined percentage after the transaction has taken place. In a brothel contract, women are left with a lot less control over what they do, how much they charge, and how much they finally earn. Plenty of incidents can threaten women's income: if a client complains about bad service, for example, the third party, who has an interest in guaranteeing the customer a pleasant experience, might return him the money, leaving the sex worker unpaid. The third party might also force women to disregard their own boundaries, such as providing services that they do not want to, working with clients that they feel reluctant to, or charging less money, if the client is only willing to pay less.

As self-employed workers in the bars and nightclubs of Tijuana's red light district, women use the venues to pick up clients, but they determine their charges and what they do, and they choose the clients themselves. Women's self-determination and control over the choice of their clients is inhibited only in clubs that perform 'line-ups.' This involves women forming a line at certain set times and clients coming forward to pick the woman of their choice. Women employed in such clubs must do one or two rotas per night as part of their contract, depending on how many women there are in total.

Débora recalls having had an unpleasant experience working in Unicorn, a club located in a remote area of south-east Tijuana. Here she expresses why she did not like the working conditions there:

\footnotetext{
${ }^{7}$ The requirement of ten fichas per night is common, which means possible additional costs of up to US $\$ 45$ to be covered by sex workers on each of their shifts.
} 
It is like slavery there, this is why I left. I did not want to continue to work there. It is bad there because you can't take time out to rest. They make you work many hours and you can only rest one day per week. There has to be two days of rest per week. Two days. I need my rest. (Débora, 22, from Tijuana)

Débora now works night shifts as a stripper at Extasis, a huge strip club on Tijuana's tourist mile, Avenida Revolución, where she feels she is treated well and generally well looked after. Working hours are more flexible at Extasis: she can take three days off per week, or even more if she likes, and work either day or night shifts.

Débora's example shows that women have a clearly formed idea of what selfdetermination and flexibility in sex work means for them, and that they seek options giving them the greatest deal of control over their work. Her statement also demonstrates women's agency in the sex trade. If women find working conditions undesirable, they leave to work in a better place. The great number and variety of sex venues in Tijuana's red light district allows women some choice with respect to their workplace. If women can choose, they select establishments that offer high earnings, respectful work relationships, and protocols that suit them. However, their choice of establishment is restricted by the value of their bodies, meaning that younger and more attractive women enjoy greater freedoms to select their work venue.

Managers remind women to stick to the sexual contracts they arrange with clients and to only offer what they are prepared to do. However, if women do not fulfil the agreed contracts inside the hotels used for the transaction of commercial sex, the management usually has little interest in intervening once the club's leaving fee for the woman has been paid by the client (generally US\$20). Women recounted that, inside clubs, managers or waiters occasionally put pressure on them to serve clients they have rejected for reasons such as appearing drunk. Waiters and managers also sometimes take the side of clients in arguments between them and sex workers. Women reported to me that waiters have argued for concessions on behalf of clients. Hence, women's 
capacity to stay in control very much depends on their ability to negotiate with staff members. Most women stressed, however, that they maintained very good relationships with most of the managers, waiters, bouncers, and hotel receptionists. They considered these kinds of interventions to be minor incidents as compared to the level of control that a brothel owner has, thereby stressing the benefits of the way Tijuana's licensed establishments in the red light district function.

\section{Self-Actualisation and Sex Work}

Sex work can be a means to self-actualisation, ${ }^{8}$ which I understand as the striving of individuals to create the person that they wish to be. Nikolas Rose (1999) has drawn our attention to the fact that individual self-actualisation in advanced capitalism has become instrumentalised to serve market demands. Current governmentality congruent with market demands - seeks to produce personal self-actualisation projects that are consumption-centred. Individuals are to assemble a 'way of life within the sphere of consumption' (Rose 1999: 230). The incitement to assemble consumptioncentred lifestyles is generated by 'technologies of consumption' (Miller and Rose 1997: 31), such as marketing and advertising. These technologies of consumption fabricate delicate affiliations between the active choices of potential consumers and the qualities, pleasures, and satisfactions represented in the product (Miller and Rose 1997: 31).

Media continually spread the signs and images of the 'good life' across the globe. Advertising and consumer culture incite individuals to be invested in the production of a lifestyle through the product choices they make. Individuals are to become 'subjects of consumption' (Rose 1999: 271), and are considered as active agents in their own consumption patterns and as creators of a lifestyle for themselves. Consumption has become an activity through which we produce, discover, and experience ourselves, and hence it has become a central part of individual projects of self-actualisation. A number

\footnotetext{
${ }^{8}$ I use the terms self-actualisation, self-realisation, self-creation, and self-making interchangeably.
} 
of scholars studying consumption have highlighted that many products are not only material objects, but also signs (Miller 2009; Baudrillard 1998). Miller (2009: 11), for instance, contends that "the heart of consumer capitalism is not "materialistic," but "semiotic." Consumption concerns the psychological world of signs, symbols, and images. Consumer goods display wealth, status, and taste, but also mental traits such as kindness, intelligence, and creativity. Baudrillard (1998) has pointed out that our societies are organised around consumption and the display of commodities through which individuals gain prestige, identity, and standing. In particular, consumer choices signal wealth, status, and belonging to a specific group; they indicate an individual's ability to live the lifestyle of a distinct group.

Carla Freeman (1998) demonstrated that women from the Global South have rapidly become consumers. D'Ougherty (2002), who investigated consumption patterns among the Brazilian middle class, underscored that consumption engages people in ongoing stratification processes, and that consumer goods can be central to strategies of boundary-making, allowing individuals to assert distance and superiority. In her study, middle-class Brazilians attained social distinction and global modernity through the consumption of imported goods. Through those practices, however, they simultaneously contributed to the local reproduction of inequalities (D'Ougherty 2002: 11).

Many women I met engaged in sex work not only to guarantee mere survival, cover their basic needs, and pay their bills: in highlighting the particular consumer choices they made, the women expressed the desire to create a particular lifestyle for themselves. Like sex workers in other parts of the world, ${ }^{9}$ they aimed to buy a house in an attractive area, purchase a fancy car, open a business, send their children to a good school, or wear clothes of a particular brand. Sex work allows some successful

\footnotetext{
${ }^{9}$ Sex workers in the Global North are not generally suspected to be 'survival prostitutes' as sex workers from the Global South often are. For a good summary of this debate, see Doezema (1998).
} 
women ${ }^{10}$ to live a different lifestyle, one not only of basic survival, but also of upward social mobility and of greater consumption.

The neoliberal market economy creates particular types of freedoms and constraints. There is a close link between women's entry into sex work and backgrounds characterised by social and economic marginalisation, lack of education, and chronic unemployment affecting generations of the same family. Many, though not all, women who enter sex work across the globe are forced to do so by a complicated mix of structural conditions, feminised care responsibilities, and exceptional hardships. However, regardless of the external coercion arising from structural conditions, some women also make an active choice for sex work, because it not only helps them manage survival, but also generates opportunities for creating a particular self and a lifestyle that they aspire to. All the sex workers I talked to had a clear understanding of the societal conditions they had grown up in, and of the limitation of opportunities resulting from that with respect to work options and the design of their personal lives. Work options equally well paid as selling sex were not accessible to them, due to the little formal education they had received. Hence, sex work represented their attempt to create a better future for themselves and their dependents.

Elisabeth is a thirty-eight-year-old indigenous woman from the southern Mexican state of Puebla. She is divorced and, apart from those months of the year when she sells sex in Tijuana, she lives with her four children and her parents in the village where she grew up. They live as subsistence farmers and just get by. 'There is no money in the house,' she said as I interviewed her. Consequently, without her income from sex work, her children would not have good clothes or healthcare, and could not go to school. Elisabeth has managed to create another life for herself and her family. This is grounded in the improved quality of life back home and is visible in certain lifestyle choices that she made for herself. Living in Tijuana, she has created a different fashion

\footnotetext{
${ }^{10}$ I have discussed who can be successful subjects in Tijuana's sex trade, and for what reasons, in Hofmann (2010).
} 
style for herself, pointing to her white trainers, blue jeans, polo shirt, and a baseball cap, she explained. Her clothes are neat and give her a youthful air. She has adopted the Tex-Mex fashion style common at the US-Mexico border, but rather exceptional in southern Mexico, particularly in small villages such as the one where she lives with her family. Elisabeth proudly tells me that she now always flies with budget airlines from Tijuana to Puebla in order to get home to help her family with the harvest or to spend Christmas with them. Sex work has enabled Elisabeth not only to enjoy a better life, but also to acquire new lifestyle expressions, which she demonstrates through fashion and a new mobility. Travelling back and forth within Mexico by plane has conventionally been a signifier of a middle-class social status. Through appropriating this means of transport for herself, Elisabeth signals upward social mobility. The income generated through sex work has enabled her not only to survive, but also to design a lifestyle for herself and her family.

During my fieldwork in Tijuana, I met Violeta, who is forty years old and who stopped selling sex a few years ago, at a local NGO that supports sex workers who have exited their profession. She took me to Plaza Rio, an outdoor shopping mall in Tijuana, for a very expensive coffee and a visit to the cinema. The plaza is not far from the USMexico border-crossing point and is frequented by Mexican middle classes and US day tourists who are after a good deal. Plaza Rio has become Violeta's favourite location for bargain hunting and window shopping. She goes there every weekend with her children to stroll around, buy clothes, toys, DVDs, and household goods, and go to the cinema whilst indulging her children with sweets and ice creams. Violeta has made a very long journey from Mexico's southern border, where she grew up in a small town. Her family comes from a socio-economically marginalised context. When she was eleven years old, her mother sold her virginity to an elderly man. When she was seventeen and became pregnant, she ran away from that relationship and hitch-hiked up north. She had her first child in Tijuana and started selling sex in the streets. Violeta has achieved immense upward social mobility, of which her participation in a traditionally middle-class consumer space - such as the shopping mall - is a signifier. 
The money that allows successful sex workers entry to these consumer spaces does not carry the stigma of the work that generated it. Money and the consumption it allows are felt to have the capacity to neutralise the negative social value attached both to these women's profession and to their former social positions at the margin of society. The notion of the respectability of money was one that several women expressed. Leticia, for instance, pointed out:

I respect my work and the money that I get for it, because it is the money that maintains my son and gives food to my family. It allows me to get ahead in life. (Leticia, 38, from Mexico City)

Money itself cannot be stigmatised. It is only an exchange medium that enables the owner to acquire goods and services. Money, in capitalist societies dividing freedoms along lines of wealth, has the capacity to transform; it allows for social metamorphosis, and it can be the gateway to a new social status. I do not want to suggest that all sex workers strive to become members of the middle class, but many aspire to certain luxuries and freedoms allowed by a middle-class lifestyle and social position.

Women told me proudly that they get around by taxi, use aeroplanes, travel, buy houses, cars and consumer goods, subscribe to the gym in their neighbourhood, join swimming clubs, and generally enjoy the luxury of having money. In a society in which consumption is so central to how people construct their identities, there is a dignity attached to middle-class living. Gaining the privileges of such a lifestyle indicates an arrival at the centre of a consumer society and, simultaneously, the exiting of spaces of exclusion and marginalisation. Money enables individuals to transform their lives; in this sense, it has become an equivalent to freedom in capitalist societies.

In this context, it is important to recognise the agency and self-empowerment that sex work allows women who are successful in the trade. The ability to lead a consumptioncentred lifestyle can contribute to a feeling of becoming 'somebody,' as opposed to remaining a 'nobody,' a person without purchasing power and the means to design a 
life course (Coy 2008: 1415). Women's entrepreneurialism, based on their own bodies, is a means for socially and economically marginalised subjects to become consumer citizens. The idea of becoming a citizen through particular consumer choices is of course a very limited form of citizenship that does not include political articulation and generative power in the public sphere.

Many sex workers I talked to saw their work as a temporary option that they chose in order to better the situations they found themselves stuck in. They have developed ways of thinking positively about themselves and their work. This thinking was characterised by ideas of progress, development, aspiration, going somewhere, creating positive change, and the like. Notions of success and self-making were central to women's narratives. Those narratives might help women master a difficult situation and remind them of their aspiration for a good life, which means not only having just enough to get by, but actually possessing the creative power to design one's course of life.

In advanced capitalism, individualistic self-creation has become increasingly important (Rose 1999; Salecl 2004; Tyler 2004). The self is seen as a canvas of unique and authentic potential that must be realised through processes of discovery, expression, and thus self-actualisation. This self-actualisation appears as a process of active 'choice' framed in terms of consumerist engagement with the idea of self as project (Bauman 1997, 1998). Currently, forms of acclaimed self-actualisation are intrinsically linked to a consumerist ideology. Individuals are encouraged to create their selves through the consumer choices they make.

The women who participated in my study all made the concession of performing intimate work with their bodies, through the course of which they were objectified. They engaged in risky and very strenuous corporeal and emotional work. Despite that, sex work was a tool that gave them the capacity to transform their lives and socioeconomic status significantly. Hence, there is agency in sex work. However, the particular agency that sex work grants is what I would call a 'precarious agency,' an 
agency that enables, but within which self-empowerment is achieved by exposing subjects to conditions bearing risks. The most prominent risks that sex workers take are health risks and physical violence. Both can be diminished by individual strategies but are not entirely erased under the current conditions of the sex industry at the USMexico border.

I would not go so far as to suggest that the women I met during my research have actually managed to become recognised as members of their local middle class because I did not conduct a long-term study, nor did I have the chance to actually witness or participate in their private lives back in their home towns. However, through their consumption patterns, they signal a no-longer-belonging to the marginalised and a desire for social mobility. Sex workers' consumption is a marker of social mobility, even if they do not reach full middle-class status because they lack the social and cultural capital required. Gramsci's remarks on cultural hegemony might help us understand why members of marginalised groups, and workers in a stigmatised profession in particular, might be drawn to display belonging to the middle class. He contends that working-class culture is devalued by the bourgeoisie, the ruling class in society that imposes its way of life on other social groups and thus establishes a 'cultural hegemony' (Gramsci 1971). By no means do sex workers want to remain associated with the marginalised group they have grown up in, and even less so with their stigmatised profession. The consumption of specific markers for middle-class status functions as signs and signals of respectability, which is what makes attempts to pass as middle class so attractive.

\section{'A Room of My Own:' Seeking Independence}

This section illustrates the complicated entanglement of women's personal desire and pursuit of independent lives with neoliberal governmentality's inducement for individuals to become self-reliant and autonomous actors. It exemplifies the operation of neoliberal rule through freedom, whereby individuals are governed through their 
own aspirations such as autonomy, self-determination, and independence (Foucault 2008; Lorey 2006; Rose 1999). Part of moving up the social ladder means for some women the acquisition of a more solitary lifestyle that allows them independence and the freedom to organise their personal lives. Some sex workers strategically seek solitude as a way of being comfortable and making themselves a home that is enjoyable and provides a relaxed and untroubled atmosphere. Rosalía described her attempt to live with another sex worker:

Look, there was a time when I shared a flat with another woman, but one can't feel comfortably at home like this. Because, sometimes one says: 'I want to lie in bed all day,' whereas the other one makes noise. Sometimes one seeks company whereas the other one rather prefers to be alone. If you share, what will you do, if a piece of paper lying around disturbs you? Sometimes it is her, sometimes me. Better everyone stays by herself. (Rosalía, 29, from Puebla)

Rosalía describes the difficulties of shared living. People have different needs and preferences. Hence, different daily rhythms and ways of living might easily clash. This is why Rosalía prefers to live alone, so that she can comfortably arrange things in her way, is not hassled, and does not need to negotiate the way things are handled in the home. Living alone is a luxury that now, as a sex worker, she can afford.

The income that some upscale sex workers make allows them the luxury of independence. For many, having their own space is an experience they have for the first time in their lives. In their home villages, towns, and cities, the majority of women lived in shared households. The dynamics of those households were determined by the requirements and needs of different people, such as the children and elderly they cared for, or the work rhythm of a partner. It is still common to find that a whole workingclass family shares a one-room apartment, which is transformed according to the necessities of the family at different times of the day (living-room, work space, bedroom). There is a power inherent to being able to pay for one's own space, namely 
the power to determine a physical space according to one's own likings - not having to make compromises or restricting oneself due to the needs of others.

Not having to communicate, for instance, but just being by oneself, can be experienced as a form of freedom. Those sex workers who can afford their own space of living enjoy the fact that this space is not reserved to accommodate the necessities of others, but belongs only to them. Sex workers who are temporarily resident in Tijuana, having left their families behind, can create living spaces that are free from pressing care responsibilities. Independence, a space for oneself, and the absence of care duties has long been the privilege of men who have withdrawn from family responsibilities. Some sex workers also desire a space of their own that allows them tranquillity and recovery from a busy work life, independence, and personal freedom.

Sex work is perceived by many women as highly demanding and straining for both body and psyche; this is why they aspire to use their spare time for relaxation and recreation. Women's acquisition of their own space is an expression of their gains in independence, freedom, and self-empowerment. Yet we can also understand sex workers' narrative of seeking solitude in the private space as an effect of their economic advancement and success. Having one's own space is a characteristic of the comfortable, affluent lifestyle that these women desire. Successful sex workers live in the same residential areas as Tijuana's middle class, where they rent nice and clean flats that provide privacy, calmness, and security, close to trendy cafés, ice-cream shops, speciality restaurants, and neat beauty salons. The residential independence that some upscale sex workers have acquired reflects their current economic success and desire for a good life.

By telling the story of a 'lonesome warrior,' women are telling a story of independence and strength. Women can avoid shared housing because they can afford it. They are no longer dependent on relationships with families or partners, because they have reached a state of affluence and financial independence. They can afford to live outside of the Zona Norte, in nicer areas offering them a higher standard of living in better 
environments and houses; they can afford to live in a one-bedroom apartment, and enjoy the luxury of living alone, not having to make arrangements, or sharing with family members or strangers. Many women I talked to experienced their 'being alone' in the home as an achievement they had gained.

I consider women's independence as an expression of their self-empowerment reached through sex work. At the same time, they also remain isolated actors who as individuals cannot supersede the negative connotations of their stigmatised profession, and achieve a higher social standing. These kinds of entanglements are characteristic of neoliberal governmentality that continually reproduces these ambivalences and injects individualising market logics into people's attempts to improve their lives.

\section{Conclusion}

This article has shown that Tijuana's sex industry does provide certain benefits to sex workers. Women consider managerial sex work arrangements preferable to personalistic ways of selling sex. Tijuana's sex industry allows a significant degree of autonomy, control, and self-determination. However, several structural aspects of the sex industry cannot be changed by women. Namely, they have no influence on the percentage that their management charges from their dances, on the prices of hotels, or on medicine they need; nor can they influence the cost of health tests, the price of the health card, or the taxes that are deducted from them. Women cannot opt out of the governmental health control for sex workers because this would make them illegal workers facing fines and imprisonment. The benefits of Tijuana's sex industry are also thwarted by the necessity of having to secure one's own safety in the red light district.

Despite the possibility of achieving self-empowerment through sex work at the USMexico border, women had some significant criticisms of the neoliberal protocols of the commercial sex industry. Sex workers raised concerns about owners of sex establishments, hotels, restaurants, bars, and nightclubs in the red light district earning 
vast amounts of money and benefiting enormously from the work of sex workers, but not offering any social security or healthcare schemes in return. Currently, Tijuana's sex industry allows successful sex workers a route to economic success and middleclass consumption practices. This personal project of self-making, however, is based on the individual's self-responsible action and shouldering of all the risks that come with the job. For instance, if women become unable to work due to infection with STDs, they have to deal with the situation on their own. Sex workers are not part of state pension schemes, nor can they receive free national healthcare services, despite the taxes that they pay into the state budget.

As this article has discussed, Tijuana's sex industry has allowed some women to become successful self-entrepreneurs, a subject position that entails both opportunity and subjection to the logic of the market. Within processes of neoliberalisation, the rules of enterprise and consumerism determine the actions and forms of agency of subjects (Penttinen 2007: 30). Consequently, individuals' means of self-empowerment are intrinsically tied to the norms and values of enterprise culture, within which the terms are defined for them. For instance, sex workers cannot influence the kinds of services that they sell on the market, nor can they change their own bodies in such a way as to correspond with the body type that currently sells at the highest price in a particular location (i.e. in relation to height, skin colour, or ethnicity). ${ }^{11}$ Just like any other actor participating in neoliberalisation, sex workers in the pursuit of selfempowerment and advancement of their lives are called upon to learn to help themselves according to the principles and means laid out by the dominating mentality of neoliberal governance.

Theorising governmentality in the context of sex work allows us to think beyond the limited dichotomy of voluntary versus forced prostitution that has dominated debates on prostitution for decades, highlighting that sex work is entangled in ambiguous and

\footnotetext{
${ }^{11}$ I have discussed mimicry, cosmetic surgery and means of increasing one's personal erotic and/or corporeal capital in Hofmann (2010).
} 
simultaneous processes: on the one hand, it generates personal empowerment and agency, and on the other hand, it increasingly demands the individual's subjection to a neoliberal market regime. Looking more closely at these ambivalences opens up a space for future research on a globalised sex industry that has taken on new shapes that are simultaneously empowering and limiting.

\section{About the author}

Susanne Hofmann holds a PhD in Latin American Cultural Studies from the University of Manchester. She is a visiting researcher at the Gender Studies Centre (PAGU) of the State University of Campinas (UNICAMP). Her main research interests are globalisation and transnational migration, the commodification of intimacy, affective labour, entrepreneurial subjectivities, neoliberalisation, and governmentality. She has published various articles on sex work in Mexico.

\section{References}

Baudrillard, Jean. 1998. The Consumer Society: Myths and Structures. London: Sage.

Bauman, Zygmunt. 1997. Postmodernity and Its Discontents. Cambridge: Polity.

— 1998. Work, Consumerism and the New Poor. Buckingham: Open University Press.

Bröckling, Ulrich. 2005. 'Engendering the Enterprising Self: Subjectification Programs and Gender Differences in Guides to Success,' Distinktion 11, 7-23.

Brunnett, Regina. 2009. Die Hegemonie symbolischer Gesundheit: Eine Studie zum Mehrwert von Gesundheit im Postfordismus. Bielefeld: Transcript Verlag. 
Castillo, Debra A. 2002. 'Interdisciplinary Work on the Line', in Anne J. Cruz, Rosalie Hernández Pecoraro, and Joyce Tolliver (eds.). Feminists at Work: Interdisciplinary Strategies by Luso-Hispanic, Latin American, and Latina Women, 1-20. Delaware: Juan de la Cuesta Hispanic Monographs.

Cornejo, Jorge A. 2002. Cuando las magdalenas devolvieron las pedradas. http://www.jornada.unam.mx/2002/07/04/ls-norte.html (accessed 15 February 2013).

Coy, Maddy. 2008 'Young Women, Local Authority Care and Selling Sex: Findings from Research,' British Journal of Social Work 38(7), 1408-24.

Dean, Mitchell. 2010. Governmentality: Power and Rule in Modern Society. London: Sage.

Doezema, Jo. 1998. 'Forced to Choose: Beyond the Voluntary v. Forced Prostitution Dichotomy,' in Kamala Kempadoo and Jo Doezema (eds.). Global Sex Workers: Rights, Resistance, and Redefinition, 34-50. New York and London: Routledge.

Foucault, Michel. 1982. 'From the Repressive Hypothesis to Bio-Power', in Hubert L. Dreyfus and Paul Rabinow (eds.). Michel Foucault: Beyond Structuralism and Hermeneutics, 126-42. Hertfordshire: Harvester Wheatsheaf.

- 2008. The Birth of Biopolitics: Lectures at the Collège de France, 1978-79 (ed. Michel Senellart and trans. Graham Burchell). Basingstoke: Palgrave Macmillan.

Freeman, Carla. 1998. 'Femininity and Flexible Labor: Fashioning Class Through Gender on the Global Assembly Line,' Critique of Anthropology 18(3), 245-262.

Gramsci, Antonio. 1971. Selections from Prison Notebooks (ed. and trans. Quintin Horare and Geoffrey Nowell-Smith). London: Lawrence \& Wishart. 
Hofmann, Susanne. 2010. 'Corporeal Entrepreneurialism and Neoliberal Agency in the Sex Trade at the US-Mexican Border,' Women's Studies Quarterly 38(3/4), 233-56.

Inda, J. Xavier. 2006. Targeting Immigrants: Government, Technology, and Ethics. Oxford: Blackwell.

Lemke, Thomas. 2008. Gouvernementalität und Biopolitik. Wiesbaden: VS Verlag für Sozialwissenschaften.

Lorey, Isabell. 2006. Governmentality and Self-Precarization: On the Normalization of Cultural Producers. http://transform.eipcp.net/transversal/1106/lorey/en (accessed 15 February 2013).

McKinley, James C. Jr. 2005. A New Law in Tijuana Regulates the Oldest Profession. http://www.nytimes.com/2005/12/13/international/americas/13prostitutes.html?_r=1\&p agewanted=all (accessed 15 February 2013).

Miller, Geoffrey. 2009. Spent: Sex, Evolution, and the Secrets of Consumerism. London: William Heinemann.

Miller, Peter and Nikolas Rose. 1997. 'Mobilising the Consumer: Assembling the Subject of Consumption,' Theory, Culture and Society 14(1), 1-26.

O'Dougherty, Maureen. 2002. Consumption Intensified: The Politics of Middle-Class Daily Life in Brazil. London: Duke University Press.

O’Connell Davidson, Julia. 1998. Prostitution, Power and Freedom. London: Polity.

Patterson, Thomas L., Shirley J. Semple, Miguel Fraga, Jesus Bucardo, Wendy DavilaFraga, and Steffanie A. Strathdee. 2005. 'An HIV-Prevention Intervention for Sex 
Workers in Tijuana, Mexico: A Pilot Study,' Hispanic Journal of Behavioral Sciences 27(1), 82-100.

Penttinen, Elina. 2008. Globalization, Prostitution and Sex-Trafficking: Corporeal Politics. London and New York: Routledge.

Read, Jason. 2009. 'A Genealogy of Homo-Economicus: Neoliberalism and the Production of Subjectivity,' Foucault Studies 6, 25-36.

Rose, Nikolas. 1999. Governing the Soul: The Shaping of the Private Self. London: Free Association Books.

Salecl, Renata. 2005. 'Worries in a Limitless World,' Cardozo Law Review 26(3), $1139-57$.

Tyler, Melissa. 2004. 'Managing between the Sheets: Lifestyle Magazines and the Management of Sexuality in Everyday Life,' Sexualities 7(1), 81-106. 